\title{
OS “CAMINHOS DE CANOA" DOS CURRÍCULOS DE UMA ESCOLA DE EDUCAÇÃO INTEGRAL EM MANAUS: CRIAÇÕES E [RE]EXISTÊNCIAS
}

\author{
Ceane Andrade Simões \\ Professora da Universidade do Estado do Amazonas/Escola Normal Superior - ENS/Uea. Mestra \\ em Educação pela Universidade do Estado do Rio de Janeiro - PPGEdu Processos Formativos e \\ Desigualdades Sociais - FFP/Uerj. \\ https://orcid.org/0000-0003-2116-1332.
}

\section{RESUMO}

Neste texto, situado no campo epistemológico-político-metodológico dos estudos nosdoscom os cotidianos escolares, discuto as possibilidades emancipatórias dos currículos na primeira escola de tempo integral mantida pelo poder público municipal de Manaus desde o ano 2016. Situada nas proximidades de um igarapé e vivendo de muito perto as intervenções urbanísticas e ambientais impostas no seu entorno, a escola se deparou com situações que ameaçavam a sua existência, a levando à tomadas de decisão políticopedagógicas e à elaboração processual de um projeto educativo fundamentado na educação integral e democrática. Aponto para a complexidade das circunstâncias envolvidas no seu dentrofora e para a diversidade de sujeitos e culturas que circulam no seu espaçotempo, com a presença de alunos haitianos e venezuelanos, chegados a Manaus em distintos processos migratórios. A fim de credibilizar suas criações e [re]existências, busquei aporte em Boaventura de Souza Santos, Inês Barbosa de Oliveira, Nilda Alves e Michael de Certeau, sinalizando também para as relações que ligam os processos de padronização dos territórios urbanos (sob o subterfúgio de [re]qualificá-los), com os de padronização curricular (sob o subterfúgio de [re]qualificar a prática docente), em prol de resultados calculáveis. Chamo de "caminhos de canoa" àquelas situações que vêm a exigir de seus praticantes engenhosidades e astúcias diárias em situações de difícil "navegabilidade" social. São experiências curriculares que abrigam o potencial de irresignação frente à razão indolente. Tais caminhos têm levado a escola a experimentar processos de desinvisibilização de saberes e sujeitos no seu cotidiano, que caracterizam as suas políticaspráticas como luta por justiça social e cognitiva e pela educação democrática.

Palavras-chave: Cotidiano escolar. Educação Integral. Currículos praticados.

\section{THE "CANOE PATH" OF THE CURRICULES OF A SCHOOL OF INTEGRAL EDUCATION IN MANAUS: CREATIONS AND [RE]EXISTENCE}

\begin{abstract}
In this text, situated in the epistemological-political-methodological field of studies in-of-with school daily routine, I discuss the emancipatory possibilities of the curricula in the first full-time school maintained by the municipality of Manaus since 2016.Located in the vicinity of a stream and living very closely the urban and environmental interventions imposed on their life environment, the school faced situations that threatened its existence, taking it to politicalpedagogical decision making and the elaboration of an educational project based on integral and democratic education.I point out the complexity of the circumstances involved in its inside-out and the diversity of issues and cultures that circulate in its spacetime, in the presence of Haitian and Venezuelan students who arrived in Manaus, in different migration processes.In order to give credibility to their creations and [re]existences, I looked for the contribution of Boaventura de Souza Santos, Ines Barbosa de Oliveira, Nilda Alves and Michael de Certeau, also pointing out the links of the normalization processes of the urban territories (under the subterfuge of [re]qualifying them), with those of curricular standardization (under the subterfuge of [re]qualifying the teaching practice), in favor of calculable results.I call "canoe path" to those situations that come to demand from their practitioners ingenuity and daily cunning in situations of difficult social "navigability".They are curricular experiences that harbor the potential for
\end{abstract}


irresolution in the face of indolent reason.Such paths led the school to experience processes of desinvisibility of knowledge and subjects in their daily routines, which characterize their politicspractices as a struggle for social and cognitive justice and for democratic education.

Key words:Schooldailyroutine. IntegralEducacion. PracticedCurricula.

\section{LOS "CAMINOS DE CANOA" DE LOS CURRÍCULOS DE UNA ESCUELA DE EDUCACIÓN INTEGRAL EN MANAUS: CREACIONES Y [RE]EXISTENCIAS}

\section{RESUMEN}

En este texto, situado en el campo epistemológico-político-metodológico de los estudios en-de-con los cotidianos escolares, discuto las posibilidades emancipatorias de los currículos en la primera escuela de tiempo integral mantenida por el poder público municipal de Manaos desde el año 2016.Situada en las proximidades de un arroyo y viviendo de muy cerca las intervenciones urbanísticas y ambientales impuestas en su entorno, la escuela enfrentó a situaciones que amenazaban su existencia, llevando a la toma de decisionespolíticopedagógicas ya la elaboración procesal de un proyecto educativo fundamentado en educación integral y democrática.Señalo a la complejidad de las circunstancias involucradas en su dentrofuera y la diversidad de temas y culturas que circulan en su espaciotiempo, en la presencia de estudiantes haitianos y venezolanos que llegaron a Manaos, en diferentes procesos de migración.Con el fin de dar credibilidad a sus creaciones y [re]existencias, busqué el aporte deBoaventura de Souza Santos, Inés Barbosa de Oliveira, Nilda Alves y Michael de Certeau,señalando también para las relaciones de vinculación de los procesos de normalización de los territorios urbanos (bajo el subterfugio de [re]calificarlos), con los de estandarización curricular (bajo el subterfugio de [re]calificar la práctica docente), en pro de resultados calculables.Llamo "caminos de canoa" a aquellas situaciones que vienen a exigir de sus practicantes ingenioy astucias diarias en situaciones de difícil "navegabilidad" social.Son experiencias curriculares que albergan el potencial de irresolución frente a la razón indolente.Tales caminos han llevado a la escuela a experimentar procesos de desinvisibilización de saberes y sujetos en su cotidiano, que caracterizan sus políticasprácticas como lucha por justicia social y cognitiva y por la educación democrática.

Palavras-clave: Cotidiano escolar. Educación Integral. Currículos practicados.

\section{“CAMINHOS DE CANOA” E CURRÍCULOS COMO IGARAPÉS: OS DESAFIOS DE} [RE]EXISTIR DA EMEF PROF. WALDIR GARCIA

Em tempos de insidiosa pressão pelo rebaixamento da vida da maioria da população empobrecida e da tentativa de padronização e controle das práticas sociais - dentre essas a educação -, encontrar outros caminhos que subvertam as relações de poderes é uma causa que desafia a todas/todos nós que acreditamos e defendemos uma sociedade democrática, social e economicamente justa e, portanto, uma educação pública democrática. Por isso, "caminhos de canoa" ou "currículos como igarapés" foi uma metáfora que formulei durante mergulho no cotidiano da primeira escola de tempo integral da Rede Municipal de Ensino de Manaus, a Escola Municipal de Ensino Fundamental Prof. Waldir Garcia (EMEF Prof. Waldir Garcia), considerando os [per]cursos, desafios e possibilidades das experiências que constituem os currículos escolares como caminho e como aquilo que 
corre como as águas. Pinar (2016), recuperando a etimologia do termo, chamou a experiência vivida do currículo de currere (o correr do curso), preferindo a forma verbal por expressar uma ação; algo em processo; de consequências contínuas, pois não acabado. Assim, arrisco a chamar tanto os currículos, quanto a ação de neles navegar, de "caminhos de canoa" - os currículos como igarapés.

Me orientando pelo campo dos estudos nosdoscom os cotidianos, naveguei epistemológica-política-metodológica para encontrar, no dizer de Oliveira (2013), as políticaspráticas curriculares (como um processo de saberesfazeres alternativos que confrontem e/ou contornem normatividades impostas) legitimamente criadas cotidianamente pelos praticantes das escolas. E, neste caso particular, as políticaspráticas curriculares criadas pela EMEF Prof. Waldir Garcia, especialmente na ocasião em que, instada pela necessidade de articular uma reação que impedisse o seu desaparecimento, foi necessário para a sua [re]existência buscar a ressignificação dos seus espaçostempos de educar. São, portanto, saberesfazeres com possibilidades emancipatórias e que por razões ético-políticas e, também, epistemológicas merecem ser credibilizados.

A EMEF Prof. Waldir Garcia está localizada na cidade de Manaus, nas proximidades do igarapé da Cachoeira Grande (afluente da Bacia do São Raimundo), situação essa que lhe impôs, direta e/ou indiretamente, tomadas de decisão políticopedagógicas que afetaram/afetam a sua vida cotidiana, uma vez que o regime das águas fluviais, os impactos causados pela degradação ambiental dos igarapés e a pressão por adensamento populacional em suas margens (BATISTA, 2013a), agravado pelo modelo de desenvolvimento econômico e urbano, produziram circunstâncias que atingiram e continuam a atingir a comunidade em que a escola se insere.

Manaus é uma cidade que foi se constituindo ao redor de uma extensa malha hídrica da qual brotam os igarapés, cursos d'água de menor profundidade e largura, que possibilitam apenas a navegação de pequenas embarcações. O termo igarapé é oriundo do tupi ygara (canoa) e pé (caminho), portanto, “caminho de canoa", e para mim evoca uma imagem interessante para pensar os currículos criados pelas práticas cotidianas da escola estudada - considerando o contexto peculiar em que se situa - e a experimentação das pequenas rotas de navegança que nele vão surgindo.

No ano de 2012, centenas de famílias do entorno da EMEF Prof. Waldir Garcia, instaladas em moradias precárias às margens do igarapé da Cachoeira Grande, no bairro de São Geraldo (Zona Centro-Sul de Manaus), foram removidas em razão das intervenções 
ambientais e urbanísticas iniciadas naquela área pelo Governo do Estado do Amazonas, por meio da Secretaria de Estado de Infraestrutura (SEINFRA) - adotando o modelo e a metodologia do Programa Social e Ambiental dos Igarapés de Manaus (PROSAMIM), com desapropriações coletivas por Interesse Público ou Interesse Social, - provocando na escola uma queda de cerca de 60\% da matrícula inicial de estudantes entre os anos de 2012 e 2016. Em seguida, em 2018, a dinâmica imposta pelas obras de infraestrutura retomadas no mês de agosto desse ano, após uma pausa de cerca de dois anos, impactou diretamente o cotidiano da escola e ameaçou de forma insidiosa a sua permanência naquela localidade.

Fruto de decisões superficialmente dialogadas com a comunidade diretamente afetada, as intervenções produziram uma massa de expropriados. O Programa previa construir moradias populares, promessa que não se concretizou no caso da área do Igarapé da Cachoeira Grande. Portanto, as famílias removidas não foram reassentadas em seu local de origem, ficando submetidas de modo precário a diferentes alternativas de reposição de moradia e indenizações previstas em lei (reassentamento monitorado, incorporação em programa de moradia popular, realocação independente, bônus ou auxílio moradia, por exemplo), conforme Batista (2013b). Conforme essa mesma autora, considerando os efeitos rastreados em outras áreas da cidade em que foi adotado, o PROSAMIM passa a configurar um caso explícito de injustiça socioambiental, tanto por transferir o ônus das mudanças às famílias menos favorecidas e pela falta de equipamentos e serviços urbanos mínimos oferecidos para atender condignamente a população, quanto por não ter assegurado efetivamente a proteção dos mananciais. Ou seja, não atendendo nem a princípios de justiça social e nem de justiça ambiental, uma vez que a metodologia adotada no Programa, no que diz respeito ao ambiente e às questões de planejamento urbano e de moradia, não foi capaz de proporcionar equidade social em escala na cidade (BATISTA, 2013b). Isso permite observar as diversas formas de violência de Estado que se espraiam nos espaçostempos da cidade. É oportuno afirmar que a interdição ou limitação do direito à moradia e à educação expressam tal violência e afetam diretamente os setores populares.

Assim, num momento inicial compreendido entre os anos de 2012 a 2016, não tendo sido concluída a requalificação urbanística e ambiental às margens do igarapé da Cachoeira Grande e nem cumprida a promessa de reassentamento das famílias na área sob intervenção, a EMEF Prof. Waldir Garcia sofreu o impacto da perda abrupta de grande parte da sua comunidade escolar. E, num segundo momento, iniciado em agosto de 2018, a própria continuidade da obra de infraestrutura na área - sem a transparência das ações 
planejadas, sem pactuação entre os poderes públicos estadual e municipal e, sobretudo, sem diálogo com a comunidade -, se tornou a fonte de perturbações e de indefinições sobre a manutenção da escola naquela localidade, levando a crer que ela seria a próxima vítima da expropriação por ação do Governo do Estado do Amazonas.

Diante da ameaça inicial de fechamento da escola pela perda massiva do alunado, tal revés, no lugar de imobilismo, produziu inconformismos e tornou seus praticantes atentos ao presente e implicados coletivamente na trama de formas outras de aprenderensinar, especialmente no que tange às dimensões assumidas na perspectiva da educação integral e da criação/experimentação de espaçostempos democráticos que foram sendo forjados no cotidiano da escola nesse processo.

Assim, parece oportuno apontar para as linhas imaginárias que ligam os processos de padronização dos territórios urbanos (sob o subterfúgio de [re]qualificá-los), com os de padronização curricular (sob o subterfúgio de [re]qualificar a prática docente), em prol de resultados calculáveis. Tais processos tendem a reduzir o espaço público (urbano e educacional) à mercadoria. Trata-se de uma potência regulativa meramente formal ou metodológica, nas palavras de Dunker (2017), para a qual as artes de fazer cotidianas (CERTEAU, 2014) e os modos singulares de inventar espaços e tempos do (com)viver configuram verdadeiro contraste, pois rompem com quaisquer formalismos aprisionadores.

A impressão é que esses processos hegemônicos padronizantes têm ido ao encontro da produção de "desertificações" dos espaços via ficção do controle, da homogeneização e da higienização dos mesmos, que escamoteiam muitos interesses contrários a torná-los (ou a assumí-los), dignamente, espaços habitáveis; espaços ocupados; espaços de convivência; espaços de criação e de pluralidade. Em lugar disso, produzem inexistências. Situação essa emblemática no território em que se localiza a escola estudada, sobre o qual intervenções urbanísticas e ambientais empreendidas pelo poder público - como é possível observar nas imagens abaixo em diferentes escalas - têm deixado a população do bairro de São Geraldo seis anos à margem de um "deserto" social, dada a situação de desassistência e de "esvaziamento" do território; e deixado a escola numa situação de quase exílio. O aterro da margem do igarapé da Cachoeira Grande vem significar isso, sendo a EMEF. Prof. Waldir Garcia, em sua luta por manter-se naquela localidade - ocupando e criando espaçostempos educativos -, a sua contraface.

Figura 1 - Desertificação. Captura de imagem de satélite em fevereiro de 2018. 


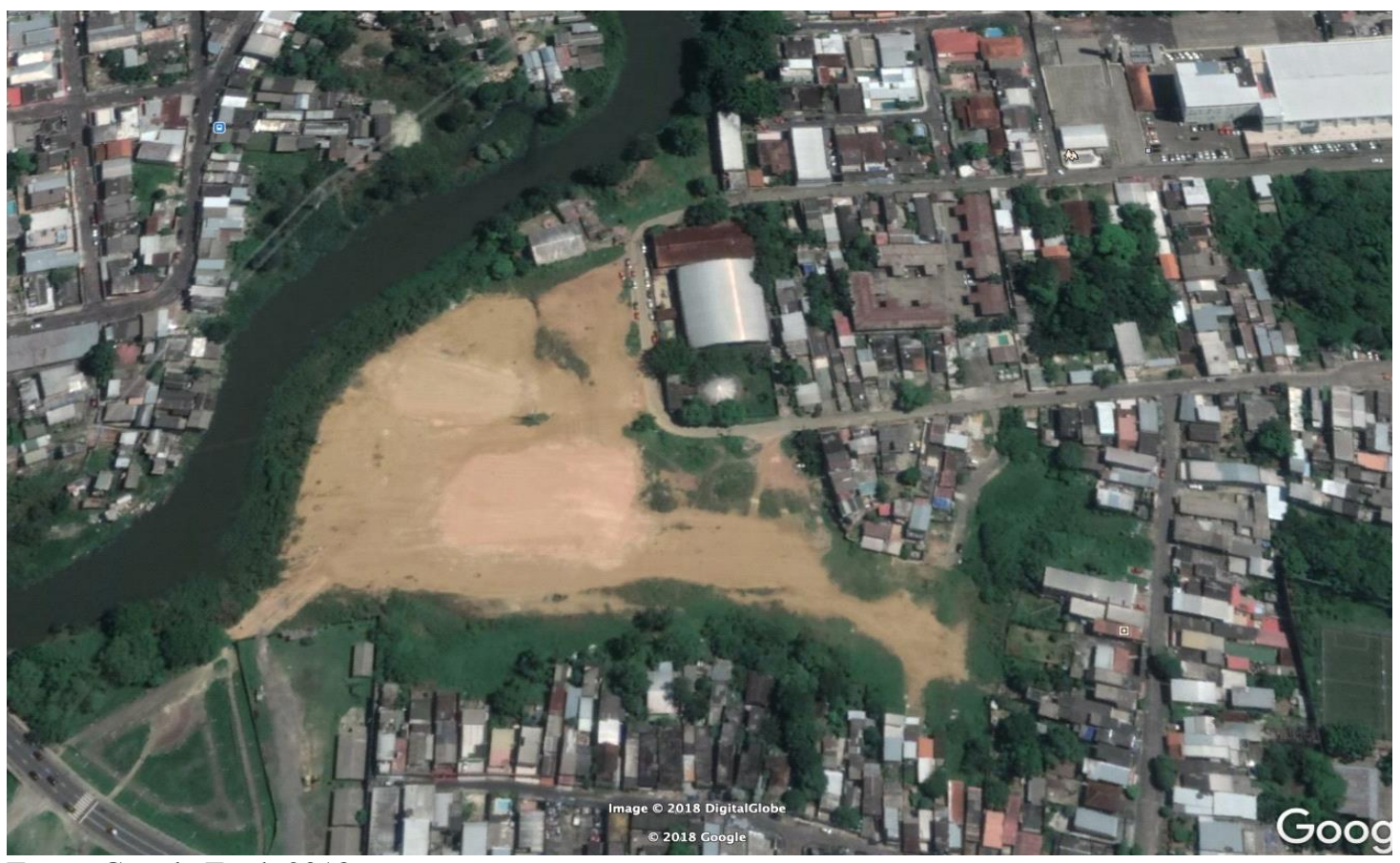

Fonte: Google Earth 2018.

Essas circunstâncias constituem elementos de complexificação da vida cotidiana da EMEF Prof. Waldir Garcia e apontam para as táticas astuciosamente atuantes neste terreno que lhe é imposto (CERTEAU, 2014) e que a convocam a [re]fezerpensar o seu projeto educativo, em busca de uma nova identidade consubstanciada na educação integral. Ou seja, a provocam a ressignificar as suas ações políticopedagógicas em dimensões mais inclusivas (de tempo, de espaço, de profissionais, de conhecimentos, entre outros).

No ano de 2016 essa escola tornou-se a primeira escola de tempo integral mantida pelo poder público municipal de Manaus, após outro advento que foi muito oportuno para essas mudanças: a pressão de um coletivo de famílias pela educação integral e democrática organizado em Manaus no ano de 2015, o Coletivo Escola Família Amazonas (CEFA). Esse coletivo tem pautado o seu ativismo na luta pela qualidade da educação pública, partindo dos princípios da autonomia pedagógica e da gestão democrática das escolas públicas municipais, experimentando também formas de participação e de diálogo nos cotidianos de outras escolas de educação integral recentemente em funcionamento na rede pública municipal de ensino, onde seus filhos e filhas participam como estudantes.

O encontro das educadoras da EMEF Prof. Waldir Garcia com o CEFA representou um "caminho de canoa" importante para a formulação de suas políticaspráticas curriculares com a educação integral, mas não o único. A experiência acumulada da escola com a participação no Programa Mais Educação e as situações em que, atenta às aflições e 
dramas que atravessam a sua comunidade, incorporou a solidariedade, o acolhimento e a empatia às suas práticas educativas, sensibilizando-se diante das lutas por moradia e vida digna dos estudantes e de suas famílias e abrindo-se para uma vivência democrática. Chamo atenção também para o fato de a escola ter se tornado um dos pontos da rede de acolhimento às crianças haitianas em idade escolar, uma vez que Manaus passou a partir do ano 2010 a ser rota de refugiados haitianos e, desde 2017, de venezuelanos, o que tem mudado as feições pedagógicas e os desafios interculturais a serem incorporados no projeto educativo da escola. As práticas já realizadas produziram conhecimentos via a elaboração cotidiana de táticas e astúcias - as quais, conforme Certeau (2014, p. 141), "formam um campo de operações dentro do qual também se desenvolve a teoria" - e, portanto, não podem ser esquecidas.

Compreendo que a pluralidade dos agentes envolvidos - entre pais e mãeseducadores/educadoras-dirigentes-representantes de movimentos sociais - na ampliação da articulação dialógica pela oferta da educação integral na rede pública municipal de ensino de Manaus, tende a uma possibilidade de aprofundamento do caráter público da educação formal, a partir da formulação de espaçostempos do agir comum - das lutas políticas voltadas à racionalidade política do comum, ou seja, das buscas coletivas de formas democráticas novas (DARDOT; LAVAL, 2017) - e da valorização da participação democrática no dentrofora das escolas, que podem estar dando espaço para formas originais de ação e discurso, sem com isso eliminar as divergências próprias desse processo.

Esse movimento de tessitura em rede que compõe o contexto das transformações vividas recentemente pela EMEF Prof. Waldir Garcia e que se encarnam às práticas curriculares dos seus praticantes, agitam o seu dentrofora, concordando com Alves (2010, p. 1197) que “(...) os muros das escolas são meras criações imaginárias, mas não indicam o que existe, no que se refere às relações entre as múltiplas e diversas redes educativas e as escolas". É preciso compreender essas redes de aprendizagemensino e as circunstâncias que a afetam e atravessam, especialmente num cenário de imensos retrocessos no campo das políticas públicas, de corte social e de "assoreamento da democracia" vividos intensamente a partir do ano de 2016 - pós-golpe parlamentar-jurídico-midiático (SOUZA, 2016) que destituiu a presidenta eleita Dilma Rousseff (PT) - e que, sequencialmente, com o acirramento dos conflitos de classe e a primazia do interesse econômico, tem operado o desmonte significativo dos direitos sociais, ameaçando garantias constitucionais e, 
culminando nas eleições de outubro de 2018, com a ascensão da extrema-direita conservadora ao poder, conjugada ao neoliberalismo, - a serviço do capital global (fenômeno, diga-se de passagem, não restrito ao Brasil, mas que por enquanto tem encontrado aqui a ambientação para exacerbar-se). Não é, portanto, surpreendente afirmar que são tempos ainda mais difíceis para os processos democráticos e para a educação pública brasileira, de modo específico.

Nas circunstâncias atuais, essa discussão importa pelo nível de complexidade e de desafios à democratização da educação e à compreensão dos currículos escolares como uma conversa complicada vivida, experimentada e dialogada na perspectiva de reconstrução de vidas subjetivas e sociais, possibilitada pela experiência educacional (PINAR, 2016), ainda que em seu percurso possam surgir contradições e ambiguidades.

Situando em nossa história recente, há, desde a década de 1990, com o avanço de políticas de cunho neoliberal, tentativas de centralização curricular - com impulso retomado na década de 2010 com a discussão das bases comuns para o currículo. E, a partir do ano 2014, em função do Plano Nacional de Educação (BRASIL, 2014), se inicia a consulta com vistas à definição de uma Base Nacional Comum Curricular - BNCC, nutrida pela promessa de, supostamente, garantir a qualidade da educação pela via da implantação dos direitos e objetivos de aprendizagem e desenvolvimento e de padrões de avaliação. Tal discurso foi ganhando terreno, embora tentando ocultar sem muito sucesso, os princípios de mercado nele contidos, uma vez que têm atuado nessa seara não apenas os agentes políticos públicos, como também, de modo proeminente, os agentes políticos privados (MACEDO, 2014).

Vale ainda lembrar, de acordo com Cavaliere (2002), que diante de uma suposta perda de identidade cultural e pedagógica da escola, da fabricação de sua crise, da ampliação das suas funções e de novas demandas sócio-integradoras, têm-se tentando ao longo das últimas décadas constituir uma nova identidade nacional para a escola brasileira. Uma das perspectivas envolve o prolongamento da jornada escolar de crianças e jovens que, sob concepções ético-políticas distintas, podem tanto significar “(...) os aspectos inovadores e transformadores embutidos numa prática escolar rica e multidimensional, como poderão ser exacerbados os aspectos reguladores e conservadores inerentes às instituições em geral" (CAVALIERE, 2002, p.250), situação essa que encontra atualmente o seu maior expoente, justamente, na aprovação da BNCC, aprofundando a lógica de padronização e de controle curricular. 
Sobre as propostas de educação integral, que não são recentes, essas vêm se diversificando sob concepções e práticas distintas (e até antagônicas), sendo requeridas por diferentes agentes políticos, com destaque, nos últimos anos, aos representantes da elite empresarial que pretensamente têm vindo a defender a "qualidade" da educação e sua "inovação" e "transformação" - fórmulas notoriamente de fácil assimilação e aceitação social, que, todavia, escamoteiam o interesse na manutenção do status quo. A prova mais recente da não univocidade do conceito de educação integral foi a (contra)reforma do Ensino Médio editada pela Lei $13.415 / 17$, tendo dentre os seus pilares a flexibilização curricular e o incremento da educação em tempo integral, bem assente com as novas formas de funcionamento empresarial e, por outro lado, com a tendência do "autoemprego" na figura do trabalhador flexibilizado (DEL ROSSO, 2017) ou do empreendedor de si.

Isso indica, conforme Cavaliere (2009), que os modelos de educação integral existentes dependem de escolhas políticopedagógicas deliberadas para encampar os sentidos da ampliação da esfera de atuação educacional e que podem produzir diferentes efeitos de natureza mais democratizante ou, ao contrário, de viés autoritário. De modo que o prolongamento do tempo de permanência de crianças e jovens nas escolas, exclusivamente, não alcança por si a efetivação do seu direito à educação de qualidade.

Há ainda uma tradição minimalista de escola, sobretudo a destinada às camadas populares, no que diz respeito à oferta de espaço, de tempo e de profissionais (CAVALIERE, 2009) num sentido tanto quantitativo, quanto qualitativo, cujas tentativas de articulação por meio de programas e políticas de educação integral no Brasil, durante as últimas décadas, têm produzido duas principais vertentes:

(...) uma que tende a investir em mudanças no interior das unidades escolares, de forma que possam oferecer condições compatíveis com a presença de alunos e professores em turno integral, e outra que tende a articular instituições e projetos da sociedade que ofereçam atividades aos alunos no turno alternativo às aulas, não necessariamente no espaço escolar, mas, preferencialmente, fora dele (CAVALIERE, 2009, p. 52).

A autora resume essas vertentes em, respectivamente, Escola de tempo integral versus Aluno em tempo integral, modelos não necessariamente cristalizados que têm colocado em questão o papel, os limites e as possibilidades das instituições escolares dentro do seu caráter público. O que preocupa são as já conhecidas e as novas tentativas de universalização do que deveria ser aprendidoensinado nas escolas a partir de um modelo 
gerencial implantado na educação, que tensiona o seu sentido público e conflita com as demandas e as práticas produzidas local e cotidianamente.

No caso particular que ora apresento, me interessa tratar dos currículos de educação integral praticadospensados no contexto da EMEF Prof. Waldir Garcia com e para além das proposições curriculares oficiais, já que o que vem sendo vislumbrado nas políticas públicas de educação parece muito diferente do conceito de educação integral socialmente referenciada que coletivos e redes de educação vêm historicamente experienciando de maneira muito singular e, portanto, apontado para um campo de disputa com uma concepção de educação (integral) que vem tentando se hegemonizar.

\section{OS MEANDROS DA EDUCAÇÃO INTEGRAL NA EMEF PROF. WALDIR GARCIA}

A EMEF Prof. Waldir Garcia, escola localizada na Zona Centro-Sul de Manaus, atua com a primeira etapa do ensino fundamental e possui atualmente 221 estudantes matriculados (distribuídos em nove turmas) - sendo parte significativa deles moradora do bairro onde a escola se situa. Entretanto, a escola tem recebido também crianças de outras zonas da cidade, tanto por se localizar em área próxima ao Centro, quanto por manter vínculo com as famílias que foram removidas das margens do igarapé da Cachoeira Grande e reassentadas na periferia de Manaus. No seu quadro docente atual conta com 18 professoras que atuam tanto com as turmas de $1^{\circ}$ ao $5^{\circ}$ ano, quanto com as oficinas (matemática lúdica, iniciação científica, iniciação à filosofia; leitura e produção textual; teatro; dança; desporto e inglês) que a escola passou a integrar ao seu currículo. A maior parte dessas professoras (75\%) é efetiva no cargo e parte significativa trabalha na escola há bastante tempo. Uma das professoras, assim como a dona Nonata, a auxiliar de serviços gerais que realizou a narrativa em epígrafe, acompanha a escola desde a sua fundação. Há também, além da diretora, duas coordenadoras pedagógicas, uma assistente social, uma secretária escolar, uma dentista, uma auxiliar administrativa, seis auxiliares de serviços gerais e dois merendeiros. Grande parte do seu quadro de apoio (auxiliar administrativa, merendeiros e auxiliares de serviços gerais) é formada por pessoal terceirizado (75\%), mas ainda assim há baixa rotatividade desses profissionais.

O prédio da escola é composto de dois pisos. No piso inferior há um hall com mesas pequenas e um jardim de inverno no desvão da escada; um corredor com bancos contínuos que leva em direção a: duas salas de aula; sala de direção compartilhada com a 
coordenação pedagógica; secretaria; sala de professores; sala de recursos; biblioteca e sala de informática (Telecentro). Há também nesse piso: gabinete odontológico; dois banheiros; sala de depósito de alimentos; cozinha e refeitório. O piso superior é composto por sete amplas salas de aula e dois banheiros. A escola está edificada sobre um grande terreno e em sua área externa há uma quadra poliesportiva, frequentada assiduamente pelos moradores dos arredores; é onde também acontecem as grades apresentações e festas da escola (com destaque para a festa junina e festival folclórico, com a apresentação do boi Garcioso); ao lado da quadra, há uma área de playgroud e, ao fundo, uma espécie de quintal onde a escola cultiva uma horta. Há também nessa área um pátio circular coberto ("chapéu de palha") e ainda duas pequenas salas de depósito de materiais desativadas, espaço que a escola deseja reformar para montar um laboratório de ciências.

A estrutura da escola passou por duas modificações ao longo dos trinta anos e nenhuma grande alteração em seu espaço foi imediatamente necessária após o ano 2016, momento em que se institui a jornada em tempo integral, a não ser pela horta que passou a ser cultivada em 2017 e do "chapéu de palha" que sofreu pequenas melhorias após reivindicação das/dos alunas/alunos. De modo geral, é possível dizer que do ponto de vista da estrutura física o do quadro de funcionários a escola encontrava-se bem guarnecida para incorporar as novas mudanças requeridas pela educação em jornada ampliada.

Parece-me interessante refletir sobre as marcas da sua recente trajetória com a educação integral, possibilitadas por um conjunto de circunstâncias vividas pela instituição que, inapelavelmente, a convocaram à incorporação do prolongamento do tempo em suas práticas educativas, a conduzindo nesse caminho para uma concepção de educação integral que vem sendo assumida pela escola, alinhada ao modelo de organização que Cavaliere (2009) formulou como escola de tempo integral, aquela em que há o fortalecimento da unidade escolar por meio da realização de mudanças em seu interior para abranger o alargamento de tarefas e responsabilidades perante o alunado, significando a incorporação articulada de mais tempo, mais espaços; mais equipamentos e profissionais com formação diversificada; com o enriquecimento da vida cultural da instituição por meio da incorporação das diversas experiências populares e a inserção de novos atores sociais em seu interior; e que toma a escola em sua condição de centralidade na formulação intencional de um projeto políticopedagógico que garanta a diversificação e o aprofundamento das vivências partilhadas entre alunos e professores em sua dimensão educativa. 
A afirmação do direito à educação integral depende das escolhas ético-políticas e da formulação de políticas públicas que fortaleçam as escolas e a consolidação dos seus projetos políticopedagógicos, promovendo de maneira condigna as condições para que a escola de tempo integral se materialize de forma democrática, garantindo com qualidade e equidade o direito à educação para todas/todos as/os estudantes, tendo em conta a complexidade (cognitiva, social, afetiva, cultura, social, simbólica) que, indissociavelmente, acompanha a formação humana. Como essas condições encontram-se em processo instituinte na esfera pública municipal em Manaus, sendo requeridas, a princípio, por pressão do movimento de famílias pela educação integral, é necessário considerar, de partida, pelo menos dois importantes desafios na experiência de educação integral vivida pela EMEF Prof. Waldir Garcia: (i) a necessidade de assunção de um compromisso ético-político e de ações afirmativas do poder público municipal pela educação integral como um direito a ser garantido às crianças e jovens e (ii) a legitimação das políticaspráticas da escola em sua dimensão emancipatória e singular, não redutíveis a uma metodologia específica ou modelização, com vistas à integração curricular de conhecimentos na perspectiva epistemológica que Santos (2010) propõe como ecologia de saberes. Isto é, buscando a desinvisibilização e a integração de diversos saberes, sujeitos e práticas no espaço legitimado da escola; saberes que do ponto de vista do pensamento hegemônico são muitas vezes considerados como "não saberes".

Considerando esses aspectos, fui tangenciando os meandros, caminhos sinuosos, percorridos pela EMEF Prof. Waldir Garcia para encontrar a si mesma dentro de uma perspectiva de educação integral, que vem reformulando a sua identidade institucional e ressignificando as suas ações políticopedagógicas cotidianas, num momento em que a sua existência institucional encontrava-se (e, de certa forma, ainda se encontra) à beira do "aterramento".

As mudanças curriculares que começam a ser desenvolvidas a partir do ano 2016, quando a escola passa a atuar em jornada integral, resultam de circunstâncias (im)postas, e, por isso mesmo, enfrentadas taticamente pelos seus sujeitos pedagógicos. Isso porque, como aponta Certeau (2014), as táticas cotidianas são as ações que se perfazem com e através das ocasiões e circunstâncias de um sistema (social) dado e sobre as quais os praticantes operam, utilizam, "fazem-com”, sutilmente invertendo as relações de força ou, pelo menos, criando possibilidades desviantes em relação à ordem estabelecida. É isso que 
se segue, por exemplo, na implantação da jornada em tempo integral na EMEF Prof. Waldir Garcia, apresentada na próxima seção.

\section{A IMPLANTAÇÃO DA JORNADA EM TEMPO INTEGRAL EM 2016 NA EMEF PROF. WALDIR GARCIA: CONTRADIÇÕES, INCERTEZAS, AMBIGUIDADES E POSSIBILIDADES}

De início, é importe afirmar, concordando com Cavaliere (2009), que o alargamento da jornada escolar de crianças e jovens não adquire valor educativo por si, sobretudo quando se trata da educação voltada para as classes populares no Brasil. Mais tempo, mais espaço e mais profissionais só são capazes de significar a sua agência de socialização e caráter educativo “(...) quando articulados em um projeto que formule os papéis que a escola brasileira pode hoje cumprir, compreendendo seus limites e contradições e as possíveis e necessárias articulações com outras instituições e processos sociais" (CAVALIERE, 2009, p.51).

Feita esta ressalva, a implantação da jornada em tempo integral na EMEF Prof. Waldir Garcia a partir ano de 2016 foi um passo inicial imprescindível para a escola e sua comunidade - apesar de, isoladamente, o prolongamento da jornada escolar ser insuficiente para concretizar um projeto de escola de tempo integral, sem isso ela inexiste, ou seja, pode não ser condição suficiente, mas é necessária - e se deu a partir de três acontecimentos que se apresentaram como "divisores de água" para a escola: (i) a perda expressiva de seu alunado em razão da remoção das moradias das famílias localizadas no entorno da escola; (ii) a experiência acumulada com o Programa Mais Educação e (iii) o encontro com o movimento reivindicatório pela implantação de escolas de educação integral que o coletivo de famílias pela educação integral, o CEFA, vinha realizando junto à SEMED. Acontecimentos que, por um lado, provocaram uma situação de ameaça à sua

existência e, por outro, abriram a possibilidade de reinventá-la. É nessa possibilidade de reinvenção que os seus sujeitos astuciosamente atuaram para garantir a [re]existência da escola e isto, necessariamente, incluiu a ressignificação do seu agir políticopedagógico com a educação integral.

A jornada em tempo integral era um anseio da comunidade da EMEF Prof. Waldir Garcia, vista inicialmente como a única chance de mantê-la de pé, mesmo porque pairava sobre a escola a ameaça de fechamento e, mais drasticamente, de demolição em 
decorrência das obras do aterro do igarapé da Cachoeira Grande, o que gerou a situação de risco iminente de seu desaparecimento. Para mantê-la funcionando era preciso resistir e demonstrar a importância que a escola tinha para o atendimento das famílias em situação de vulnerabilidade social e o caso mais evidente era o dos haitianos que passaram a se concentrar no bairro onde fica localizada a escola. Ao narrar a situação de fragilização da escola, a Profa. Lúcia Cristina, diretora da escola, vai sinalizando que a sua razão de existir dependia do que ela nomeou de "atrativo", ou seja, a possibilidade de extensão do tempo de permanência das crianças justificada, primeiramente, pela necessidade de acolhimento social, que já era algo presente na história dessa escola dada a situação de pobreza extrema e exclusão social que marca a comunidade em que está inserida. Ter sensibilidade para tal não era necessariamente uma opção e foi esta característica que permitiu à escola continuar existindo e resistindo. Como dito pela diretora sobre a necessidade da jornada em tempo integral:

Já era de interesse da escola há algum tempo, nós queríamos que a escola passasse a ser de tempo integral. Nós havíamos perdido o Programa Mais Educação porque não havia mais verba para continuarmos a manter o programa na escola e tinha que ter o tempo integral, pois era o único atrativo que nós tínhamos para que os pais trouxessem os filhos de longe. Também havia os haitianos que necessitavam que seus filhos passassem o dia na escola, os pais que moravam longe - os que foram removidos do entorno da escola por causa do PROSAMIM - e as pessoas que trabalhavam no centro da cidade e que deixariam os seus filhos na escola para passar o dia. Ou seja, o tempo integral era o único atrativo que eu tinha para que os pais dos alunos que estavam matriculados não pedissem transferência e para que a escola pudesse receber alunos novos. Então, a escola já desejava o tempo integral. Eu já havia solicitado da Secretaria de Educação, lutando há dois anos, por meio de audiências com os secretários, para externar o desejo, a necessidade e a carência que, principalmente os estrangeiros tinham. E nós queríamos acolher, principalmente porque já realizávamos isso com essas crianças pelo Programa Mais Educação, então nós precisávamos do apoio da Secretaria para o tempo integral, pois era necessário alimentação e funcionários para atuar como monitores. E, sempre argumentando em razão dos custos, os secretários diziam que não queriam criar uma "ilha" na Secretaria. Se a escola Waldir Garcia passasse a funcionar em tempo integral - porque só se falava em "tempo" e não em educação integral -, ela seria "uma ilha". E não era do interesse da Secretaria criar "ilhas" porque se não pudesse ser para todos, não seria para ninguém, segundo eles.

(Profa. Lúcia Cristina dos Santos, diretora)

A fala da diretora Lúcia Cristina situa inicialmente a jornada em tempo integral na escola dentro de sua função estritamente assistencialista e reconhece “(...) só se falava em 
‘tempo' e não em educação integral” naquele contexto e ainda assim era visto como uma "ilha" (de "privilégios"?), que eu chamaria de nem-para-todos-e-nem-para-ninguém, no âmbito da educação municipal, evidenciando a compreensão precária dos conhecimentos e normas que regem o tema da educação integral. A vasta produção acadêmica e as experiências brasileiras acumuladas nesse campo (MAURÍCIO, 2009; MOLL; et alii, 2012), bem como a legislação educacional trazem determinações e esclarecimentos a respeito da questão. A Lei de Diretrizes e Bases da Educação Nacional (Lei no 9.394/96) recomenda, em seu Art. $34^{\circ}:[\ldots] \quad \xi 2^{\circ}$ O ensino fundamental será ministrado progressivamente em tempo integral, a critério dos sistemas de ensino; os Planos Nacionais de Educação (PNE 2001-2010, Lei n. 10.172, de 09/01/2001 e PNE 2014-2024, Lei n. 13.005, de 25/06/2014) e há o próprio compromisso assumido pelo poder público municipal de Manaus por meio do Plano Municipal de Educação - PME 2014-2024 (Lei. N. 2.000, de 24/06/2015), que estabelece em sua meta 6: Oferecer educação em tempo integral em, no mínimo, cinquenta por cento das escolas públicas municipais, de forma a atender, pelo menos, vinte e cinco por cento dos alunos da educação básica municipal, reproduzindo literalmente a meta estabelecida no PNE 2014-2024.

A esse respeito, Gabriel e Cavaliere (2012) apontam que a educação integral no Brasil abriga uma polissemia inevitável, ainda mais quando está em questão a reavaliação da esfera de atuação da escola e da ampliação de suas responsabilidades, frente à situação de injustiça social e econômica a que grande parcela da população brasileira é submetida, de tal forma que a visão de seu papel compensatório e assistencialista compõe o mosaico de sentidos presentes no tecido social em torno do tema e coloca em jogo, na arena de discussão pública, tanto os limites quanto as possibilidades da escola. Assim:

(...) a utilização do conceito de educação integral, quando referido à escola contemporânea, não é autoevidente. Ele resulta da reavaliação do papel da instituição escolar, ou seja, relaciona-se à busca de limites e possibilidades de atuação da instituição escolar. Daí a sua inevitável polissemia" (GABRIEL; CAVALIERE, 2012, p. 201).

Uma apreciação mais crítica e profunda dessa questão é oferecida por Arroyo (2012) quando advoga pelo direito a tempos e espaços de um justo e digno viver das infâncias-adolescências, reconhecendo que a existência de um viés assistencialista na educação integral é sustentado por uma visão negativa das infâncias-adolescências populares, vistas sob o prisma do risco e da vulnerabilidade social e moral, que concorrem para a manutenção da subalternização e da inferiorização das camadas populares. 
Programas e políticas de educação integral que não partam de visões afirmativas sobre esses sujeitos, seus corpos e seus modos de vida "Nem sequer serão pensados como políticas e ações distributivas, compensatórias, supletivas de carências intelectuais, mas de carências morais" (ARROYO, 2012, p. 37) e não darão conta de conceber e efetivar a educação como um direito humano básico.

Se mais tempo na escola (ou em turno extra fora dela) ocorre sob o registro moralizante e assistencialista em relação aos filhos das camadas populares, o seu significado políticopedagógico nos programas e políticas de educação integral, segundo Arroyo, não será apenas antipedagógico, mas também antiético, pois tais programas e políticas "estarão cumprindo um papel histórico funesto: reforçar históricas visões negativas, preconceituosas, segregadoras e inferiorizantes das culturas populares e de suas infâncias e adolescências que com tanto custo chegaram às escolas" (ARROYO, 2012, p. 37). Assim, esse autor aponta que é preciso pôr em disputa na sociedade (e nas práticas escolares) outras visões sobre as infâncias-adolescências populares, outro imaginário social e político sobre os setores populares. É a disputa por uma concepção de sociedade que está em questão!

Além disso, é preciso ter claro que:

A precarização das formas de vida das crianças e adolescentes populares não é um acidente momentâneo a ser resolvido com programas pontuais. Menos ainda pode ser reduzido a um condicionamento dos processos escolares de gestão ou de ensino-aprendizagem a ser descondicionado com turnos extra para algumas escolas (ARROYO, 2012, p. 37).

Estas são questões que precisam ser enfrentadas pelo conjunto da sociedade, e especificamente pelo coletivo de educadoras/educadores e redes de educação pública, para pensar projetos educativos ancorados na educação integral e nas presenças afirmativas das/dos estudantes e da comunidade no cotidiano das escolas. Portanto, atendendo a uma dimensão emancipatória da educação.

Por isso, analiso que foi dentro de um campo de contradições, de incertezas e até de ambiguidades em torno da educação integral que a EMEF Prof. Waldir Garcia retirou efeitos imprevistos para produzir o seu projeto educativo, formulando nas suas operações cotidianas - as quais Certeau (2014) nomeia de arte de utilizar, de fazer-com, de usos - as possibilidades para a sua reorganização pedagógica, para atender de maneira afirmativa e digna a vida de sujeitos já historicamente vitimados pela exclusão; vidas precarizadas nos espaços e tempos do precário viver (Arroyo, 2012). 
PERDA DA COMUNIDADE, URBANISMOS IMPOSTO E NOVOS SUJEITOS NA ESCOLA

Por conta da "perda da comunidade" - como costuma dizer a diretora Lúcia Cristina -, no processo de esvaziamento de suas turmas e, supostamente, do seu próprio sentido de existir naquela localidade, a escola vinha funcionando com seis, das nove turmas que poderia atender por turno. Durante os anos de 2014 a 2015, três salas prosseguiam fechadas e sem perspectiva de a situação ser revertida em curto prazo. $\mathrm{O}$ receio de perda de mais alunos/alunas rondava os corredores da escola. A ameaça de sua destruição continuava viva e fazia parte de uma lógica perversa. Para os "interventores urbanos", agentes políticos do Estado responsáveis pelo programa de "saneamento social e ambiental" que cuidou da remoção de centenas de moradias situadas na margem do igarapé no entorno da escola - com a sua visão higienista de um urbanismo imposto, velho conhecido da cidade de Manaus desde os fins do século XIX -, a escola se constituía apenas como um obstáculo sem importância. A lógica atual de intervenção governamental no espaço urbano manauara parece não estar muito distante daquela das intervenções urbanas pretéritas às quais a cidade foi submetida historicamente, pois, como apontam Valle e Oliveira (2003, p. 160):

O desprezo pela cultura local e a supremacia da cultura imposta são visíveis nas formas do espaço urbano de Manaus, os obstáculos são removidos para dar lugar na selva a uma cidade "digna" e sem os males dos trópicos, para receber "os civilizados". A segregação está na lógica de produção da cidade, visto que a cidade não é produzida e apropriada igualmente. Manaus não era uma cidade para todos, nem sem males para todos. Havia no urbanismo proposto no final do século o signo da exclusão. Os excluídos eram os pobres, os índios e os caboclos.

Como lembra a canção do compositor Zeca Torres e do poeta amazonense Aldísio Filgueiras, Porto de Lenha / Tu nunca serás Liverpool / Com uma cara sardenta e olhos azuis, a cidade digna (sem aspas) para todos/todas ainda é uma realidade distante, pois o urbanismo que negou o "porto de lenha" - traduzido nos modos singulares de viver à beira das águas - é o mesmo que ainda segrega e exclui. Aos excluídos sociais de antes e de agora - pobres, índios, "caboclos”, principal contingente da migração interna - somaramse os migrantes haitianos, que começaram a chegar a Manaus no ano de 2010 e os venezuelanos, mais recentemente, tornando ainda mais distante o delírio da "Paris dos 
Trópicos" nutrido no início do século XX ou da "Miami brasileira" (FREIRE, 2015) do final desse século. Ou ainda, no dizer de Dias (1999, p. 32), carregado de ironia: "É a modernidade que chega ao porto de lenha, com sua visão transformadora, arrasando com o atrasado e feio e construindo o moderno e belo".

Sobre a questão do atual fluxo migratório externo na cidade, de acordo com Silva (2016), a partir de estudo realizado junto à Pastoral do Migrante de Manaus durante os anos de 2012 e 2013, chegaram a Manaus por volta de oito mil imigrantes haitianos, dos quais permaneceram cerca de mil. Assim, segundo o autor, a cidade pareceu se tornar um lugar de "passagem" para outros centros urbanos dos estados do Sul e do Sudeste. Entretanto, cabe compreender os fatores implicados nas "escolhas" daqueles/daquelas que permaneceram e como tem sido o processo de inserção sociocultural. De acordo com o autor, os imigrantes haitianos foram recebidos com alguma desconfiança por parte dos manauaras que os viam como fonte de ameaça num contexto de restrição de empregos. Havia também os manauaras que se ressentiam do acolhimento dado aos haitianos e seus filhos na Igreja Católica de São Geraldo, um dos locais de atendimento da Pastoral do Migrante de Manaus, localizada no bairro onde a EMEF Prof. Waldir Garcia se situa.

Contudo, as opiniões se dividem sobre tal presença no bairro. Para alguns, prevalece a questão humanitária e, inclusive, apoiam as ações sociais que têm sido feitas em favor desses imigrantes. É o caso de José Carlos, engenheiro de 55 anos e morador do bairro há doze anos, o qual ajudou na acolhida dos haitianos, inclusive oferecendo dinheiro. Para ele, a relação é tranquila, pois na sua visão eles "são educados e vieram para ficar”. Já para Carlos, de 45 anos e morador do bairro há quinze anos, as autoridades deveriam atender primeiro as necessidades dos brasileiros, pois, segundo ele, "o governo dá aos haitianos prioridade que nunca foi dada aos amazonenses". A mesma visão é compartilhada por Marlene, de 62 anos e que tem uma filha desempregada. Para ela, o padre dá mais apoio aos estrangeiros do que aos moradores locais, inclusive cedeu-lhes a quadra de esporte, local antes utilizado pelas crianças da comunidade. Outros dizem não se importar com a presença haitiana, mas acabam reproduzindo a visão corrente de que eles vieram para ocupar vagas no mercado de trabalho, as quais deveriam ser reservadas em primeiro lugar aos amazonenses, ideia, aliás, recorrente em diferentes contextos migratórios, particularmente, em momentos de retração econômica. (SILVA, 2016, p. 143).

A integração sociocultural dos imigrantes haitianos, e agora também dos venezuelanos, aponta para a complexidade e dificuldade da questão, diante dessas múltiplas variáveis presentes no cotidiano da EMEF Prof. Waldir Garcia, mas, também, confirma a sua importância como um dos pontos da rede de acolhimento aos imigrantes e a 
sua responsabilidade no enfrentamento do racismo e na consideração das questões de diferença e identidade racial no seu currículo, para dizer o mínimo. Por outro lado, também significou que dar visibilidade e considerar a existência de grupos socialmente excluídos, era também uma questão de dar visibilidade e considerar a necessidade de existência da própria escola. Segundo dados da secretaria da EMEF Prof. Waldir Garcia, dos 221 alunos/alunas matriculados/matriculadas no ano de 2018, 13\% têm nacionalidade estrangeira. E essa tem sido uma questão social importante a afetar os currículos da escola e as redes de conhecimentos nela tecidas, no contexto da educação integral.

A esse respeito é interessante destacar que, algum tempo depois dos apelos realizados pela diretora Lúcia Cristina à SEMED para implantação da jornada em tempo integral na escola, é somente em janeiro de 2016 que esta possibilidade vem a ser ventilada. Como lembra a diretora:

(...) liga a "Secretaria" e pergunta se nós queremos (a jornada em tempo integral). Eu disse: é tudo o que nós queremos! Então marcaram uma reunião em que já estavam presentes vocês (se referindo ao CEFA), a "Secretaria" (se referindo à subsecretária de gestão educacional e chefes de departamentos da SEMED) e a DDZ para propor e sugerir. Agora eu te digo, sem vergonha nenhuma da minha ignorância, eu só fui saber, conhecer a diferença entre educação em tempo integral (horário integral) e educação integral em 2016 quando vocês trazem o projeto e nos apresentam.

Desde 2015, a escola de tempo integral foi a pauta mobilizada pelo coletivo de famílias pela educação integral, o CEFA, junto à SEMED. Esse ano havia sido marcado por ações protagonizadas pelo coletivo que solidariamente se organizou em função do tema (reuniões, debates e seminários e busca de articulações sobre e para a educação integral em tempo integral) e consolidou o movimento de famílias pela educação integral em Manaus. $\mathrm{O}$ aprofundamento das reivindicações do CEFA junto à SEMED resultou na apresentação de uma proposta de criação de uma escola de educação integral, com a explicitação dos princípios que orientariam o seu projeto políticopedagógico, atendendo a uma solicitação da própria SEMED. Naquela altura, a proposta recebeu a atenção da secretária de educação e da subsecretária de gestão educacional, entretanto, a possibilidade de criação de uma nova escola que correspondesse à concepção e à estrutura explicitadas no projeto esbarrava em questões administrativas, financeiras e operacionais sinalizadas pela SEMED.

Conforme aponta Arroyo (2012), a construção de ações, programas e políticas públicas com base na educação integral surge das demandas dos movimentos sociais, a 
partir da década de 1990, das vitórias obtidas com a publicação do Estatuto da Criança e do Adolescente (1997) e da Lei de Diretrizes e Bases da Educação (1996), como forma de enfrentamento das muitas vulnerabilidades das crianças e adolescentes e de aprimoramento contínuo da qualidade da aprendizagem. Ainda segundo esse autor, a educação integral surge junto a uma elevação da "consciência política de que ao Estado e aos governantes cabe o dever de garantir mais tempo de formação, de articular os tempos-espaços de seu viver, de socialização" (p.33). Para além da questão da vulnerabilidade social, os movimentos discutiam e ainda discutem questões relativas à reorganização curricular, à não fragmentação dos tempos, espaços e campos de saber, à autonomia dos educandos na construção de percursos de aprendizagem, aos professores como mediadores do conhecimento e à articulação comunitária e participação das famílias na gestão e operacionalização das instituições de ensino. Não por acaso, são essas as bandeiras trazidas pelo CEFA e que também estavam presentes no projeto apresentado à SEMED.

Apesar de já haver sido elaborado pela SEMED no ano de 2013 o documento designado Proposta Pedagógica de Tempo Integral da Rede Pública Municipal de Manaus e de, no mesmo ano, haver sido editada uma resolução pelo Conselho Municipal de Educação regulamentando o funcionamento de escolas com jornada em tempo integral em Manaus (Resolução n. 29/CME/2013, de 18 de dezembro de 2013), inexistia uma política consolidada para a educação integral no âmbito do município, em que pese os dados registrados no Censo Escolar 2010-2013 indicarem a existência de 32.586 matrículas de tempo integral em escolas urbanas e rurais de Manaus, possivelmente referentes ao Programa Mais Educação.

Diante disso, após muitas conversas e idas e vindas, foi apontada a situação da EMEF Prof. Waldir Garcia e a possibilidade de implantação da educação integral nessa escola já no ano de 2016. Dada a premência do início do ano letivo, pareceu uma alternativa viável à SEMED propor a mudança à direção da escola e, ao mesmo tempo, atender em parte as reivindicações trazidas pelo CEFA, já que deixava em suspenso a fundação de uma escola nova, o que veio a acontecer no mês de abril do mesmo ano.

Naquela altura, junto ao projeto de criação de uma escola de educação integral, o coletivo também solicitou à SEMED a constituição de um grupo de trabalho com a participação de gestores e técnicos da Secretaria, educadores/educadoras das escolas interessadas no tema e o CEFA, com o objetivo de avaliar as dimensões da proposta apresentada, mas, sobretudo, como modo de ampliar a implicação com a pauta da educação 
integral naquela esfera. Constituído formalmente esse grupo, ele recebe o nome de Comissão de Elaboração e Monitoramento da Educação Integral (ou GT de educação integral). Apesar das discussões de natureza pedagógica que se iniciam nesse grupo desde 2015, ficava cada vez mais claro que a decisão pela fundação de escolas de educação integral sob a responsabilidade do poder público municipal de Manaus dependia de uma escolha ético-política a ser assumida e do adequado estudo sobre as condições de melhoria da infraestrutura e espaço físico das escolas, alimentação, suficiente quadro de professores, formação continuada dos docentes etc., aspectos esses que só foram dimensionados concomitantemente à implantação da jornada em tempo integral na EMEF Prof. Waldir Garcia, que de certa forma inaugura ou coloca como questão concreta a escola em tempo integral na agenda política da SEMED. Todavia, as questões conceituais e pragmáticas foram tentando ser respondidas num processo que ainda está em curso e que tem sido bastante dependente do protagonismo das escolas que aderiram ao movimento e de suas urgências. Como assinala a diretora da EMEF Prof. Waldir Garcia, Profa. Lúcia Cristina:

Quando nós decidimos começar, nós queríamos para ontem! Eu lembro bem que a "Secretaria" sugeriu o início do tempo integral para maio ou junho e nós dizíamos não, ou iniciávamos em fevereiro ou não teríamos alunos porque os pais não esperariam março, abril, maio e junho, eles tirariam os alunos e eu não poderia perder mais nenhum, já havia pouco! Então a "Secretaria" pergunta, mas como vocês vão começar em fevereiro? Nós já tínhamos toda a experiência do Programa Mais Educação, das crianças passarem o dia na escola, e nós puxamos essa responsabilidade enquanto escola, junto com a equipe, e decidimos começar em fevereiro. Reunimos os pais, apresentamos a proposta e colocamos: "vocês tem a opção de decidir ficar em tempo integral ou vocês podem tirar as crianças da escola, é aberto isso". Então os pais decidem que querem e precisam que seus filhos passem o dia na escola, apenas três pais retiraram os seus filhos, e a gente inicia! Então, nós comunicamos à Secretaria: a gente vai fazer!

\section{A GENTE VAI FAZER!}

A decisão (“a gente vai fazer!”) quanto às mudanças sentidas como urgentes, requereram a implantação da jornada em tempo integral como oportunidade que a escola não poderia - com a sua existência em jogo -, desperdiçar (assim como as suas experiências acumuladas com o Programa Mais Educação não poderiam ser!) e que lhe fizeram atuar em condições incertas, mas também por meio delas. São as táticas e as 
astúcias do oprimido operando golpe por golpe, "gestos hábeis do 'fraco' na ordem estabelecida pelo 'forte'”, conforme Certeau (2014, p. 98).

Diante da decisão da escola, coube à Comissão de Elaboração e Monitoramento da Educação Integral (a qual a diretora da escola também integrava), com a participação do CEFA, apoiar as/os educadoras/educadores no seu processo formativo e acompanhar a implantação da jornada em tempo integral, inicialmente partindo do documento norteador formulado anos antes pela SEMED e das discussões e sessões de estudos realizadas nesse grupo de trabalho sobre o tema da educação integral. Então, a diretora Lúcia Cristina analisa algumas das decisões tomadas pela própria escola em relação aos rumos do seu currículo, deixando entrever a importância do fato de a escola exercitar a sua autonomia pedagógica e, com este ato, tornar existente e credibilizar os seus saberesfazeres. Isso por si abriga enorme potencial emancipatório:

(...) A escola passa a ser um laboratório e nós começamos decidindo o que nós queríamos. E a gente já começa implantando as assembleias e as tutorias. Então foi muita experimentação e nós decidindo quais as oficinas seriam realizadas, os tempos das oficinas, quem seriam os professores. Quer dizer, foi uma coisa que partiu da escola, de escolher com o coletivo e isso foi bom para nós. E quando eles começam a ter questionamentos do tipo "Mas isso não dá certo!", mas como não dá certo se nós já estamos fazendo? Então eles vêm à escola, o próprio conselho (municipal de educação), vão à sala de aula, reúnem com os pais que estavam aguardando a saída dos filhos, nos pegam de surpresa, conversam com os alunos. Nesse dia veio um monte de conselheiro que eu nem sabia que existia, um monte de gente. Então nós fizemos uma roda de conversa e eles começam a nos perguntar o que é um projeto de vida, o que é a tutoria, o que é o grupo de responsabilidade, o que é um roteiro de estudo e nós os levamos às salas para verem que não é só "papel" ou um sonho, nós fazemos e está dando certo.

Com esse ímpeto, a EMEF Prof. Waldir Garcia foi assumindo o significado políticopedagógico do prolongamento do tempo na escola e o desafio cotidiano de pensarfazer os seus espaçostempos educativos (posto que indissociáveis) para encontrar os seus achados alegres, poéticos e bélicos (CERTEAU, 2014), fazendo experimentações ao seu modo - com e para além dos documentos oficiais curriculares disponíveis até aquele momento -, o que exigiu, e exige ainda, um engajamento considerável de toda a equipe para manter a atenção ao presente e às possibilidades nele contidas, singrando pelos [per]cursos meandrosos que os/as trouxeram até este momento.

Enquanto isso, a Comissão de Elaboração e Monitoramento da Educação Integral da SEMED continuava a discutir as dimensões da nova proposta pedagógica de educação 
integral para a rede pública municipal de ensino de Manaus, tentando de algum modo integrar o que a EMEF Prof. Waldir Garcia vinha experimentado ao longo de 2016.

A nova proposta pedagógica formulada recebeu a designação de "Proposta Pedagógica de Educação Integral para o Município de Manaus nos Anos Iniciais" (MANAUS, 2016) e foi encaminhada ao Conselho Municipal de Educação em agosto de 2016, sendo aprovada no mesmo ano por meio da Resolução CME n. 020/2016. Apesar do empenho manifestado pela SEMED em formular um documento de referência para as suas ações políticopedagógicas quanto à educação integral, esse deve ser percebido dentro do seu caráter parcial, provisório e também contraditório, uma vez que a referida comissão optou por elaborar os marcos balizadores da educação integral focalizando apenas os anos iniciais do ensino fundamental, de modo a dar abrigo institucional às mudanças protagonizadas pela EMEF Prof. Waldir Garcia.

À guisa de uma breve apresentação, esse documento propõe como objetivo geral:

Instituir a Educação Integral em tempo integral nas escolas públicas com inequívoca qualidade, assegurando formação plena a todos os estudantes, fundamentada em práticas democráticas, inclusivas, sustentáveis, social e culturalmente justas (MANAUS, 2016, p. 11).

E, em resumo, está constituído por oito tópicos, a saber: (1) Breve histórico da educação integral; (2) Aspectos legais da educação integral; (3) Comunidade de aprendizagens; (4) Currículo; (5) Planejamento e avaliação; (6) Organização dos espaços e tempos; (7) Caminhos para instituir a educação integral em novas unidades de ensino e (8) Estrutura curricular dos anos iniciais. Não cabe no âmbito deste trabalho realizar uma análise mais apurada do teor desse documento, de suas condições de produção e de seus efeitos, mas aponto que ele tem natureza mais pragmática do que propriamente filosófica e conceitual, seguindo a esteira do desenvolvimento de competências e habilidades dos estudantes, porém integradas a temas sociais a serem desenvolvidos no âmbito dos conhecimentos da chamada "base nacional comum" do currículo (Língua Portuguesa, Arte, Educação Física, Matemática, Ciências, História, Geografia e Ensino Religioso) e da sua "parte diversificada" (Língua estrangeira moderna; Literatura; Atividades artísticas; Atividades esportivas; Educação matemática; Iniciação científica e Filosofia) nas práticas cotidianas da escola. Aparentemente, o que se propõe é mais educação do mesmo tipo de educação (ARROYO, 2012). Apesar disso, o documento sinaliza também para a abrangência e a consideração de outros saberes a serem incorporados no currículo, em articulação com o território, com a família, a comunidade e a tecnologia: 
A Educação Integral busca o aprimoramento do planejamento - na variedade de oportunidades de aprendizagem -, da diversidade dos espaços e da ampliação de tempos, em estreita articulação com o território, a comunidade, a família e as novas tecnologias. Portanto, assume a importância dos conhecimentos proporcionados por essa articulação, integrando-os aos saberes sistematizados no currículo. Sendo assim, possibilita responder aos padrões de qualidade exigidos pela legislação vigente, para atender às exigências de uma formação voltada para o mundo contemporâneo que se torna cada vez mais complexo e dinâmico (MANAUS, 2016, p. 7).

Contudo, no tópico 7 (Caminhos para instituir a educação integral em novas unidades de ensino) a SEMED abre mão de assumir um compromisso com a escola de tempo integral em Manaus quando informa para as escolas que decidirem adotar a referida proposta de educação integral que:

Não há condicionantes de estrutura física a priori, ainda que deva haver um compromisso da Unidade Escolar em trabalhar no sentido de adaptar gradualmente os seus recursos para atingir os objetivos de um Projeto Político-pedagógico de Educação Integral. A implantação da proposta de Educação Integral pode ser um processo gradual e os primeiros passos podem ser tomados independentemente de uma adesão à Educação Integral em Tempo Integral. (A opção de uma Unidade Escolar pelo funcionamento em tempo Integral não a obriga a aderir à proposta de Educação Integral (MANAUS, 2016, p. 40).

Em resumo, a confusão e a ambiguidade explicitadas no texto e a não garantia de estrutura física "a priori", deixa a cargo das escolas, e de um quase completo espontaneísmo e voluntarismo, os rumos da escola de tempo integral em Manaus. Por fim, a Proposta Pedagógica de Educação Integral para o Município de Manaus nos Anos Iniciais, como política, aponta para uma perigosa armadilha: escola de tempo integral sem o tempo integral e sem a educação integral. Deste modo, concordando mais uma vez com Cavaliere (2009), as escolhas ético-políticas-filosóficas quanto a um modelo de educação integral jamais serão inócuas. A sua afirmação como um direito dependerá de uma longa disputa na esfera pública para o aprimoramento das políticas que fortaleçam as escolas e a consolidação dos seus projetos políticopedagógicos no horizonte da educação integral.

\section{A CANOA SEGUE: ALGUMAS CONSIDERAÇÕES NÃO CONCLUSIVAS}

O esforço neste texto foi o de, acercando as circunstâncias e singularidades da EMEF Prof. Waldir Garcia, ressaltar o momento em que a escola se "lançou nas águas da 
educação integral", buscando credibilizar os seus modos de [re]existência assumidos. Eles foram constituindo uma trama curricular emancipatória, em minha avaliação, o que a levou à experimentação de novos espaçostempos curriculares (assembleias dos estudantes, tutorias, grupos de responsabilidade e oficinas), a partir de 2016, e criou a possibilidade de uma compreensão compartilhada das responsabilidades educativas de todos os praticantes. Tais práticas a conduziram à percepção de uma "comunidade de aprendizagem", como se referem as/os educadoras/educadores. Isto se deu, por exemplo, com a proposta das oficinas realizadas na escola. Ainda que as turmas se mantenham organizadas em classes (do $1^{\circ}$ ao $5^{\circ}$ ano), há, por meio das oficinas, a interação de cada professora com todas as crianças durante a semana (uma vez que as mesmas também são os responsáveis pela realização dessa atividade curricular), enfatizando práticas coletivas de aprenderensinar não mais restritas às professoras em sua "classe" ou ao monitor/oficineiro nas oficinas, o que tem ampliado a percepção de uma responsabilidade compartilhada pelos alunos/alunas por parte das professoras e, por outro lado, a oportunidade de um convívio maior das crianças com todas elas. Não por acaso, o encontro e a convivência também são dimensões da concepção de escola em tempo integral que, reconhecendo a integralidade da pessoa, mediada pela multiplicidade de linguagens, circunstâncias e atividades desenvolvidas em espaçostempos plurais, proporciona o seu desenvolvimento integral, associando o tempo de permanência na escola ao incremento da qualidade do trabalho (MAURÍCIO, 2009). Assim:

Só nesta convivência longa e diária serão formuladas as condições coletivas que tornem produtivo o convívio de necessidades e culturas diversas, dos próprios alunos e de professores e alunos. Haverá tensão, haverá conflito, mas a compreensão desta função da escola permitirá que se encontrem os meios indispensáveis para a realização deste projeto. Tempo e espaço aqui tornam-se condições para formular propostas que tenham o encontro, a convivência, como eixo para desenvolver conhecimento (MAURÍ́CIO, 2009, p. 27).

Além disso, a presença de crianças de origem haitiana e venezuelana, bem como de crianças com necessidades especiais incluídas nas classes regulares, tem provocado o espaçotempo da escola para a abertura às suas experiências plurais e conhecimentos singulares. Sobretudo esses primeiros têm vindo a ser reconhecidos como "intérpretes na relação entre a escola e as suas famílias", não apenas quando são chamados para traduzirem as conversas entre as/os educadoras/educadores e seus pais e mães com dificuldades com a língua portuguesa, mas porque vêm realizando, com a escola, a 
tradução dos muitos conhecimentos que trazem consigo e que vêm sendo incorporados às práticas pedagógicas. A multiculturalidade visível nas feições da escola, "É um caminho sem volta!", como concluiu a Prof. Kátia, da oficina de Teatro, reconhecendo a importância da presença e da valorização das diversidades (cultural, social, etc.) no contexto da escola. E assim, a escola tem assumido os vários desafios dos seus temposespaços de aprendizagemensino, nas suas diversas redes.

As discussões aqui apresentadas possuem suas marcas históricas, dinâmicas e passíveis de mudanças, assim como as águas que correm. Por isso mesmo, o futuro da escola de tempo integral em Manaus segue no fluxo das incertezas políticas, mas isso não quer dizer resignação das/dos educadoras/educadores. A educação integral como política pública em Manaus necessita de aprofundamento e de consolidação para se tornar uma política afirmativa e que contribua para que as escolas públicas municipais possam experimentar os seus projetos políticopedagógicos tramados a muitas "mãos". Assim, a experiência em curso na EMEF Prof. Waldir Garcia aponta para a necessidade de tornar visíveis e credíveis projetos emancipatórios de educação integral no município de Manaus em sua perspectiva democratizante.

\section{REFERÊNCIAS}

ALVES, Nilda. A compreensão de políticas nas pesquisas com os cotidianos: para além dos processos de regulação. In: Educ. Soc., Campinas, v. 31, n. 113, p. 1195-1212, out.dez. 2010.

ARROYO, M. O direito a tempos-espaços de um justo e digno viver. In MOLL, Jaqueline; et al. Caminhos da educação Integral no Brasil: direito a outros tempos e espaços educativos. Porto Alegre: Penso, 2012, p. 33-45.

BATISTA, Selma Paula Maciel. Algumas considerações sobre as intervenções do PROSAMIM no ordenamento da cidade de Manaus. In: Revista Geonorte. Edição especial 3, V. 7, n. 1, p. 1376-1393. 2013a. ISSN 2237-1419. Acesso em 10 de abril de 2017.

BATISTA, Selma Paula Maciel. Injustiça socioambiental: o caso PROSAMIM. 287f. Tese de Doutorado na área de concentração em Geografia Humana. Faculdade de Filosofia, Letras e Ciências Humanas da Universidade de São Paulo. São Paulo. 2013b.

BRASIL. Lei No 13.005, de 25 de junho de 2014. Aprova o Plano Nacional de Educação PNE 2014-2024 e dá outras providências. 
CAVALIERE, Ana Maria Villela. Educação integral: uma nova identidade para a escola brasileira? Educação \& Sociedade, v. 23, n. 81, p. 247-270, 2002.

CAVALIERE, Ana Maria. Escolas de tempo integral versus alunos em tempo integral. MAURÍCIO, Lúcia Velloso (Org.). Em Aberto n. 80, vol. 22. Instituto Nacional de Estudos e Pesquisas Educacionais Anísio Teixeira - INEP. Abril 2009. p. 51-63.

CERTEAU, Michel de. A invenção do cotidiano: 1. Artes de fazer. Ephraim Ferreira Alves (Trad.). 22. ed. Petrópolis, RJ: Vozes, 2014.

DARDOT, Pierre; LAVAL, Christian. Comum: ensaio sobre a revolução no século XXI. Mariana Echalar (trad.). São Paulo: Boitempo, 2017.

DEL ROSSO, Sadi. O ardil da flexibilidade: os trabalhadores e a teoria do valor. São Paulo: Boitempo, 2017.

DIAS, Edinea Mascarenhas. A ilusão do fausto: Manaus - 1890-1920. Manaus: Editora Valer, 1999.

DUNKER, Christian. Subjetividade em tempos de pós-verdade. In: DUNKER, Christian; et all. Ética e pós-verdade. Porto Alegre: Dublinense, 2017. p. 9-42.

FREIRE, Ribamar Bessa. Manaus, a Miami brasileira. Manaus, janeiro de 2015. Disponível em <http://www.taquiprati.com.br/cronica/656-manaus-a-miami-brasileiraserie-manaus-vii> Acesso em: 12 de março de 2018.

GABRIEL, Carmem Teresa; CAVALIERE, Ana Maria. Educação Integral e currículo integrado. Quando os dois conceitos se articulam em um programa. In: MOLL, Jaqueline; et al. Caminhos da educação integral no Brasil: direito a outros tempos e espaços educativos. Porto Alegre: Penso, 2012. p. 278-294).

MACEDO, Elizabeth. Base Nacional Curricular Comum: novas formas de sociabilidade produzindo sentidos para educação. In: Revista e-Curriculum, São Paulo, v. 12, n. 03 p.1530 - 1555 out./dez. 2014 ISSN: 1809-3876.

MANAUS. Resolução No 29/CME/2013, de 18 de dezembro de 2013. Institui as diretrizes para organização e funcionamento das unidades de ensino em tempo integral/turno único da rede municipal de ensino de Manaus e fixa procedimentos para a implementação da proposta pedagógica das unidades de ensino em tempo integral.

MANAUS. Secretaria Municipal de Educação. Proposta Pedagógica de Tempo Integral da Rede Pública Municipal de Manaus. 2013.

MANAUS. Secretaria Municipal de Educação. Proposta Pedagógica de Educação Integral para o Município de Manaus nos Anos Iniciais. 2016.

MAURÍCIO, Lúcia Velloso. Escritos, representações e pressupostos da escola pública de horário integral. In: Educação integral e tempo integral. MAURÍCIO, Lúcia Velloso (Org.). Em Aberto n. 80, vol. 22. Instituto Nacional de Estudos e Pesquisas Educacionais Anísio Teixeira - INEP. Abril 2009. p. 15-34. 
MOLL, Jaqueline; et al. Caminhos da educação integral no Brasil: direito a outros tempos e espaços educativos. Porto Alegre: Penso, 2012.

OLIVEIRA, Inês Barbosa de. Currículo e processos de aprendizagemensino: políticaspráticas Educacionais Cotidianas. Currículo sem fronteiras, v. 13, n. 3, p. 375391, set/dez. 2013.

PINAR, William. Estudos Curriculares: ensaios selecionados. Alice Casimiro Lopes; Elizabeth Macedo (organização e revisão técnica). São Paulo: Cortez, 2016.

SANTOS, Boaventura de Souza. A gramática do tempo: para uma nova cultura política 3. ed. São Paulo: Cortez, 2010 - (Col. Para um novo senso comum; v. 4).

SILVA, Sidney Antônio da. Entre o Caribe e a Amazônia: haitianos em Manaus e os desafios da inserção sociocultural. In: Estudos Avançados. v. 30, n. 88. p. 139-152. Disponível em <http://www.scielo.br/pdf/ea/v30n88/0103-4014-ea-30-88-0139.pdf>. Acesso em: 24 de abril de 2018.

SOUZA, Jessé. A radiografia do golpe: entenda como e por que você foi enganado. Rio de Janeiro: LeYa, 2016.

VALLE, Arthemisia de Souza; OLIVEIRA, José Aldemir de. A cidade de Manaus: análise da produção do espaço urbano a partir dos igarapés. In: OLIVEIRA, José Aldemir; ALECRIM, José Duarte; GASNIER, Thyerry Ray Jehlen. (Orgs.). Cidade de Manaus: visões interdisciplinares. Manaus: EDUA, 2003 p. 151-184.

Recebido: 05/03/2019

Aceito: 30/03/2019 